\title{
Dar con el jefe. Las autoridades indígenas y los registros coloniales (Tucumán y Nueva Vizcaya, siglos XVI y XVII)
}

\section{(1) Christophe Giudicelli"}

Fecha de recepción: 23 de agosto de 2017. Fecha de aceptación: 6 de noviembre de 2017

\begin{abstract}
Resumen
El presente trabajo trata la identificación de las autoridades indígenas en las fuentes coloniales en dos tierras de frontera de la América española, el Tucumán y la Nueva Vizcaya, entre finales del siglo XVI y principios del XVII. La figura del jefe está omnipresente en los registros coloniales, tanto en los documentos administrativos como en los que tratan de la guerra. Sin embargo, la aparición de esta figura suele ser problemática y ambigua. Los "caciques", "curacas", "principales", etc. aparecen tanto como emanación autónoma del grupo al que representan o como figuras necesarias para la gestión burocrática colonial; como líderes rebeldes o responsables designados por las instancias hispano-criollas para representar un contingente previamente sometido. A partir de estudios de caso, el artículo propone algunas pistas de reflexión para ver en qué medida se puede distinguir en las fuentes la identificación de un jefe emanado de la sociedad indígena del nombramiento heterónomo de un cacique, funcional al orden colonial.
\end{abstract}

Find the chief. Indigenous authorities and the colonial documentary corpus (Tucumán and Nueva Vizcaya, $16^{\text {th }}$ and $17^{\text {th }}$ centuries)

\footnotetext{
Abstract

The current paper deals with the identification of indigenous authorities in colonial sources, in two borderlands of the Spanish Empire, Tucumán and Nueva Vizcaya, between the late $16^{\text {th }}$ and early $17^{\text {th }}$ centuries. The figure of the chief appears to be omnipresent in colonial documents, in administrative

* Université Rennes 2/ Centre National de la Recherche Scientifique (CNRS) - (CRED), Unité Mixte de Recherche (UMR) 7227. équipe Collectif Histoire et Anthropologie, Colonialités et Altérités (CHACAL). Rennes 2, Francia. E-mail: cgiudicelli. terra@wanadoo.fr
}

\section{Palabras clave}

fuentes coloniales autoridades étnicas Tucumán

Nueva Vizcaya

\section{Key words}

colonial sources ethnic authorities Tucumán Nueva Vizcaya 
1. Según Foucault: “El espacio disciplinario tiende a dividirse en tantas parcelas como cuerpos o elementos que repartir hay. Es preciso anular los efectos de las distribuciones indecisas, la desaparición incontrolada de los individuos, su circulación difusa, su coagulación inutilizable y peligrosa; táctica de antideserción, de antivagabundeo, de antiaglomeración. Se trata de establecer las presencias y las ausencias, de saber dónde y cómo encontrar a los individuos, instaurar las comunicaciones útiles, interrumpir las que no lo son, poder en cada instante vigilar la conducta de cada cual, apreciarla, sancionarla, medir las cualidades o los méritos" ([1976] 2002: 146-147). files as well as in documents referring to war. Its recurrent apparition, though, is almost always problematic and ambiguous. The "caciques", "curacas", "principales" and so on show up either as autonomous emanation of the group they represent and as necessary figures of the bureaucratic colonial organisation. They were rebel leaders and also representatives chosen by Hispano-Creole instances to represent a previously submitted contingent. This article poses a few hypotheses in order to distinguish in colonial sources a leader who effectively takes its power from within its society from a cacique appointed by the colonial order, whose position is mainly heteronymous.

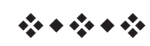

En este trabajo, quisiéramos interrogar la cuestión de las autoridades indígenas en las fuentes coloniales relativas a dos escenarios de frontera en su primer siglo de existencia: el Tucumán, en el confín sudeste del virreinato del Perú, y la Nueva Vizcaya, perdido en el noroeste del otro virreinato, la Nueva España. En los documentos de archivo abocados a delimitar y definir un grupo indígena, una de las obsesiones más recurrentes es la identificación de un jefe. Esta figura de autoridad aparece bajo una variedad importante de nombres: cacique, curaca, principal, mandón, gobernador, rey o reyezuelo, etc., que por supuesto no son equivalentes y a veces se superponen.

Lo que nos interesa aquí es tratar de encarar esta figura de autoridad en sus diferentes facetas y, más particularmente, bajo la doble perspectiva de la representación política -el jefe como emanación autónoma del grupo al que representa, muchas veces como líder "rebelde"- y el "jefe", "cacique", "curaca", etc., como figura necesaria de la gestión burocrática colonial; es decir, como responsable ante las instancias hispano-criollas en tanto desempeña la función metonímica de representar determinado contingente generalmente rotulado como nación o parcialidad.

La identificación de esta figura del jefe es una constante en las fuentes relativas al mundo indígena. Esto no debe sorprendernos en la medida en que esta designación de un jefe, de un responsable o de un portavoz, es un dispositivo central del "poder disciplinario" cuyo despliegue implica delimitar, aislar y segmentar unidades discretas para integrarlas en un diagrama de control, ${ }^{1}$ una acción consubstancial a cualquier empresa de toma de control de un territorio y de sumisión de sus habitantes.

Uno de los fundamentos de la presente interrogación apunta precisamente a entender de dónde viene esta obsesión colonial de "dar con el jefe", cuál es su función y, en segundo lugar, observar que a esta obsesión le sucedió otra, dentro de nuestras disciplinas, gobernada por otros imperativos: la preocupación por reconstruir la estructura política de las sociedades indígenas a partir de los documentos de archivo que manejamos.

Empezaremos, por lo tanto, por distinguir esas dos obsesiones de índole bastante diferentes pero que paradójicamente convergen con notable frecuencia: por un lado, la identificación/entronización sistemática de "caciques" por las instancias coloniales, central en los documentos de archivo y; por el otro, la preocupación constante, en el campo de la antropología histórica y/o la etnohistoria por aislar, mediante el tratamiento de esos mismos documentos, a los que detentaban la autoridad política. Esta voluntad es, la mayoría de las veces, motivada por un imperativo que todos los que trabajamos estas temáticas compartimos: la reconstrucción de la autonomía, el rescate de la agencia de las sociedades en cuestión, para emplear una palabra demasiado 
a menudo empleada como una fórmula mágica pero que, lamentablemente, no nos exime del trabajo de descodificación, crítica y deconstrucción de los documentos estudiados.

El problema que se nos plantea, a los que manejamos documentos de archivos relativos a los confines de la América española en el primer siglo de lenta configuración de la mal llamada "frontera", es que este tipo de información sobre las sociedades indígenas es sumamente determinado y, sobre todo, unívoco, no contradictorio. Los datos que rescatamos en el variopinto y lacunario corpus que manejamos -documentos de encomienda, partes de pacificación, correspondencia de gobernadores y cabildos, informes misionales...- vienen signados por la información que han sufrido previamente por parte de los dispositivos coloniales. Y esta información, en la inmensa mayoría de los casos, casi nunca se puede contrastar con otro tipo de documentos procedentes de los mismos actores. De ahí la necesidad de adoptar un escepticismo metodológico radical, de desconfiar no sólo de lo que parecen decir las fuentes antes de que se las torture para que canten sino también de los resultados pre-formateados por los marcos teóricos con los que pretendemos encarar los documentos coloniales.

\section{Hambruna archivística / Espejismos teóricos}

El caso es que estas precauciones apotropaicas cobran una importancia particular a la hora de acechar aunque sea los atisbos de una autonomía indígena en el corpus archivístico de esas zonas tan peculiares, como son los confines coloniales.

Si para las zonas nucleares -el Anáhuac, el Perú central y algunas pocas regiones más- las autoridades indígenas pudieron dejar huellas de su actuación como tales en el juego político registrado en los archivos, por ejemplo bajo la forma de memorias enviadas al Consejo de Indias y quejas judiciales elevadas mediante algún protector de indios; ${ }^{2}$ para las zonas que trabajamos este recurso prácticamente no existe. Para la Nueva Vizcaya y el Tucumán -los Valles Calchaquíes, para más señas-, hasta mediados del siglo XVII los documentos en los que aparece una voz indígena son extremadamente raros y muy problemáticos. ${ }^{3}$ Ahora bien, como el hambre es mala consejera, este tipo de documento con sabor especial suele ser objeto de un tratamiento de excepción que, muchas veces, opaca las condiciones de aparición de tal o cual sujeto indígena eminente en el legajo considerado. En concreto, impide ver que ésta obedece a determinada construcción lógica que no necesariamente nos acerca a la "realidad" -con todas las comillas que merece la palabra- ni tampoco a la organización política del grupo del que emanan las pocas voces de "caciques" que llegaron hasta nosotros, mediatizadas por las fuentes. ${ }^{4}$

Con esto queremos decir simplemente que la aparición de una voz indígena en un legajo no siempre permite sortear la heteronomía que rige la presentación de los grupos indígenas en las fuentes en las que se escuchan esas voces; algo observable en las principales clases de manuscritos en los que se manifiestan como: pleitos por tierra, documentos laborales -relativos a la encomienda en particular- e informes de pacificación -generalmente confesiones de cautivos rebeldes al pie de la horca o ya engrillados en una collera de piezas esclavizadas.
2. Cunill (2015) estudia, por ejemplo, el acceso de los indios mayas del Yucatán a la justicia colonial.

3. Con eso no queremos decir que los indígenas de estas peculiares zonas de frontera estén ausentes de las fuentes sino que su capacidad de acción y de representación era infinitamente más limitadas que en las zonas nucleares mencionadas. Para el Tucumán colonial en los siglos XVI y XVII abundan los documentos en los que aparecen indígenas, sean caciques o no. De hecho el presente trabajo se funda en una investigación de varios años en los principales acervos archivísticos sobre las regiones consideradas. Esta documentación -pleitos, títulos y posesiones de encomienda, padrones de encomienda, mercedes de tierras y testamentos-se encuentra en particular en el Archivo Histórico de la Provincia de Córdoba (AHPC) -en particular secciones Escribanía 1 y 2-, varios fondos del Archivo General de la Nación en Buenos Aires (AGN, Buenos Aires) -sobre todo Sala IX-, el Archivo Histórico de Tucumán (AHT) -secciones judicial civil, judicial criminal, Protocolos I y Protocolos II- y, en menor medida, en el Archivo y Biblioteca Históricos de Salta (ABHS) -en particular, Fondo de mercedes de tierras y solares-, el Archivo y Biblioteca Nacional de Bolivia de Sucre (ABNB), la sección de manuscritos de la $\mathrm{Bi}$ blioteca Nacional de Brasil (BNB) -fondo Pedro de Angelis-, amén del inagotable Archivo General de Indias de Sevilla (AGI) -en particular ramos Charcas, Escribanía de Cámara, pero también Buenos Aires, Indiferente General y Lima. (continúa en página 30).

4. La abundante presencia de sujetos indígenas y más específicamente de "caciques" en la documentación colonial no es en absoluto garantía de autonomía. Para las tierras que nos ocupan, es decir tierras de confines en los primeros tiempos de su conquista, salvo muy contadas excepciones la aparición de esos sujetos en la documentación viene rigurosamente ajustada a las necesidades administrativas que presiden a su redacción.
Dicho de otro modo, por muy apetecibles que parezcan estos documentos -pues dan la ilusión de aplacar un poco la hambruna archivística en la que 
5. Según el modelo algo idealizado acuñado por Gonzalo Lamana (2008) para los primeros tiempos del Perú colonial. Ese modelo nos parece de por sí discutible $y$, en todo caso, totalmente inadaptable a la situación que prevalece en los márgenes ultra violentos de la Nueva Vizcaya y del Tucumán en la época considerada.

6. En referencia al irenismo, tendencia filosófica nacida en el siglo XVII que privilegiaba una actitud conciliadora hasta el extremo de querer reconciliar las posiciones más opuestas -como por ejemplo las diferentes iglesias cristianas. tratamos de sobrevivir-, el riesgo de tomar gato por liebre es fuerte, en concreto, de ver la agencia donde lo que tenemos tiene mucho más que ver con un agenciamiento. El riesgo de fetichización de las así llamadas "fuentes indígenas" es tan fuerte que fue analizado colectivamente en un dossier temático publicado hace unos años en la revista Corpus bajo la coordinación de Guillermo Wilde (2013). Este autor prevenía en esa ocasión contra el

[...] problema de los usos historiográficos contemporáneos de los documentos coloniales, utilizados para construir realidades étnicas estáticas, las cuales actúan como espejismos o ilusiones ópticas que ocultan las realidades sociales locales (Wilde, 2013: 5).

Por eso nos parece necesario redoblar estas precauciones metodológicas en lo referente a la identificación de autoridades indígenas: la aparición de un cacique de carne y tinta no siempre nos da acceso a la organización autónoma de la sociedad indígena cuyo funcionamiento quisiéramos entender o reconstruir. El que hable en primera persona raras veces nos da a escuchar interpelaciones mutuas, ${ }^{5}$ entre una entidad autónoma encarnada en la figura representativa del cacique y las instancias hispano-criollas que consignan sus palabras en un documento regido por una lógica que no tiene nada que ver con el marco de un irénico ${ }^{6}$ y bastante tópico intercambio entre iguales. De modo que no nos exime de una ingrata tarea de triangulación con otro tipo de documento y de otra clase de materiales.

\section{Dar con el jefe}

Vamos a centrarnos ahora en las figuras más comunes del cacique en el corpus relativo a la confrontación colonial de las regiones consideradas. Como ya lo mencionamos, esta figura comprende dos facetas: es un elemento clave del sistema colonial y un dispositivo central de la construcción de la pax hispánica. Esos dos polos entre los que se manifiesta son, por un lado, el "cacique de encomienda" y, por el otro, el jefe "rebelde", candidato al poco envidiable estatuto de trofeo de pacificación.

\section{Cacique de encomienda}

La figura sobresaliente de un jefe, un líder, aparece, según las circunstancias y las situaciones de enunciación, bajo diversos nombres; en un contexto generalmente anterior a su integración en el espacio disciplinado de la frontera, aparece como: "rey", "reyezuelo", "el que manda a esa gente", "capitán" y, muchas veces como "cacique", a secas. Este último es un término vigente en la totalidad de la América española, alternando a veces con el de "curaca" en el área andina -incluso en el Tucumán- sin que eso remita necesariamente al sentido original de uno u otro término ni a su perímetro de aplicación inicial. Los más proclives a usar la palabra "curaca" fueron los misioneros de la Compañía de Jesús, sobre todo en sus primeros años en la provincia -a principios del siglo XVII- cuando lanzaban misiones volantes desde Salta y San Miguel de Tucumán. Las Cartas Anuas de la Compañía de los años 1610-1620 evocan con cierta regularidad a unos "curacas" para designar a los líderes del sector central del Valle de Calchaquí (Lorandi y Boixadós 19871988), llegando por ejemplo a evocar a un tal "[...] don Juan Calchaqui, ques el mas principal curaca de todos los demás con otros tres curacas." ${ }^{7}$ El que el uso de este concepto haya sido recurrente entre los padres de la Compañía (1927-1929 (XX): 75-77). 
cuando era casi nulo entre los demás agentes coloniales del Tucumán no debe sorprender: los redactores de esas primeras Anuas procedían de la Provincia jesuítica del Perú (Maldavsky (2012) y transferían lógicamente a la realidad sociopolítica indígenas las herramientas conceptuales que habían utilizado en su labor entre los ayllus del ex Tawantinsuyu. De hecho, con el tiempo, el uso de la palabra desapareció casi por completo de sus informes, a pesar de contadas hesitaciones en algunos documentos que llegan por cierto a alternar "curaca" y "cacique" para designar a la misma persona. ${ }^{8}$

A su vez, estos dos términos cobran un sentido muy diferente según su contexto de aparición en la documentación. En el caso de confrontación en situación de autonomía -en documentos que describen los primeros encuentros y aluden a negociaciones o a enfrentamientos-, el "cacique" -o el "curaca"- cae del lado de la categoría política del "rey" o "reyezuelo", viene a recubrir un supuesto liderazgo interno a la sociedad indígena descrita en las fuentes. Ahora, si por el contrario la evocación de esas autoridades aparece en el marco de las relaciones coloniales, la figura del cacique cobra un sentido mucho más mecánico y sobre todo determinado: aparece como una pieza de la maquinaria colonial, en tanto "cacique de repartimiento", o "cacique de encomienda". Su función consiste en representar al contingente delimitado -la encomienda- en la economía de control de la colonia. En otras palabras, en este marco el cacique es, ante todo, un engranaje necesario, carente per se de toda autonomía -recordemos que tanto en el Tucumán como en la Nueva Vizcaya, para la época, las encomiendas que se extendían a los colonos se presentaban siempre bajo la forma siguiente: el nombre del contingente afectado por la distribución y el o los caciques que debían presentarse ante las autoridades para que la posesión de la encomienda fuera efectiva.

Podemos citar al respecto, a título de ilustración, la atribución por el teniente de gobernador de Santiago del Estero, Iñigo Ramírez de Velasco, de la encomienda de Animaná, en el Valle Calchaquí en 1592, a un prominente potentado de Salta, Juan de Abreu: ${ }^{9}$

[...] hago merced y depósito real a vos, el dicho Juan de Abreu de Figueroa, vecino de la ciudad de San Felipe de Salta, conforme a la encomienda que teneis en términos de la dicha ciudad, en el Valle de Calchaquí, del pueblo llamado Amimaná con el cacique Chuchut, que ha pocos años se pobló en el dicho asiento, con los demás caciques e indios del dho pueblo. ${ }^{10}$

El cacique es por lo tanto indisociable de la encomienda, por no decir consubstancial a la misma. Es imprescindible dar con él para asegurar la cohesión y más concretamente para velar por el respeto a las prestaciones exigidas por el encomendero. Sirve para asegurar el éxito de las levas decretadas en el marco de la mita o el repartimiento. Dado el grado de arbitrariedad que presidía al recorte de las encomiendas, sujetas a mil "composiciones" y por lo tanto a la aparición de mil nuevos caciques, sobran razones para cuestionar el carácter autónomo del cargo del cacique-de-encomienda. Para limitarnos al caso de los Valles Calchaquíes, se sabe que el intento de poblamiento de un nuevo asentamiento en el corazón del Valle en 1630 -Nuestra Señora de Guadalupese financió gracias a la renuncia por parte de los encomenderos antiguos de una tercera parte de sus tributarios. Los vecinos feudatarios de Salta o de San Miguel de Tucumán poseían encomiendas desde la fundación de esas dos ciudades pero casi nunca habían podido sacar beneficio de ellas por la mala voluntad de los calchaquíes, quienes tomaban las armas al primer intento de presión. ${ }^{11}$ Eso explica por qué esos encomenderos aceptaron de buena gana
8. Es el caso, por ejemplo, del litigio que opuso en 1650 don Ramiro, hijo de Juan Chalimín, líder de los Malfines durante el Gran alzamiento de los años 1630, a su primo Utisamaya, al que acusa de usurpación de cargo por su colaboración con las fuerzas de represión hispan-ocriollas. El documento evoca a "Utisa maya yndio curaca principal del pueblo de malfin de la encomienda de don Isidro de Villafañe", pero a continuación todo gira en torno al cargo de cacique y al derecho de cacicazgo que reclama don Ramiro como derecho hereditario (AHPC: Esc. $1^{\circ}$, Leg. 79 , Exp. 1 y Esc. $1^{\circ}$, Leg. 94, Exp. 7). El caso es parcialmente reproducido en Montes (1961):145156.

9. Era hijo del gobernador Gonzalo de Abreu, y, para la fecha, uno de los mandamases de Salta. Existe un voluminoso expediente sobre el juicio que le hizo al sucesor y asesino de su padre, el licenciado de Lerma. (BNBA-García Viñas, Vol. 123, no 2166. Pleito de don Juan de Abreu contra el Lic. Lerma). Los autos del juicio ocupan también la casi-totalidad del volumen siguiente.

10. AGN, Archivo Ángel Justiniano Carranza, leg. 651. Depósito de los indios encomienda del pueblo de Amimaná a Juan de Abreu por Iñigo Ramírez de Velasco, 03-06-1592.

11. Una situación deplorada con notable regularidad por las autoridades hispano-criollas. Véase por ejemplo, para principios del siglo XVII la Carta al rey del gobernador Alonso de Rivera, fechada el 26-021611 (BNBA, Fondo García Viñas n. 4131). 
12. AHT, Protocolos vol. 2, fs. 281291. Renuncias a indios de encomiendas en la corona. Fundación de una villa en el Valle Calchaquí: Nuestra Señora de Guadalupe, sitio de Samalamahao.

13. Encomienda de la que tuvo confirmación oficial en 1596. AGN. Angel Carranza. Leg. 651: Posesión de los indios encomienda del pueblo de Amimaná a Juan de Abreu, 14-09-1596.

14. AHT. Protocolos, vol. 2, fs. $285 \mathrm{v}$ 286v. (el destacado en cursiva es nuestro).

15. AGl. Charcas, 102, n. 2.

16. ABNB. EC. 18-1634. Capítulo de carta que escribió el capitán Francisco de Arias desde la ciudad de Salta a veinte del mayo pasado de mil y seicientos y treinta y cuatro años, con relación de lo sucedido en esta entrada que hizo. Boixadós (2011) propone una presentación de este documento.

17. AGl. Charcas 102, nํ 2 (los interrogantes son nuestros). Notemos de paso la alternancia, una vez más entre "cacique" y "curaca". renunciar a una parte de su feudo -poco más que virtual- para favorecer el proyecto del gobernador Felipe de Albornoz. ${ }^{12}$ El objetivo de esta medida de dudosa legalidad era doble: le permitía al gobernador Albornoz crear nuevas encomiendas para retribuir a los futuros vecinos de la villa y les dejaba a los vecinos de Salta y San Miguel alguna esperanza de que con el proceso de pacificación del Valle sus indios de encomienda quedasen sometidos a su autoridad, cosa que nunca habían logrado hasta entonces. Así es por ejemplo como, el 3 de febrero de 1630, Pedro de Abreu y Figueroa, hijo del ya citado Juan de Abreu y Figueroa, del que vimos que había recibido en encomienda el pueblo de Animaná en $1592,{ }^{13}$ hizo "[...] dejación de [...] la tercia de los indios de su encomienda del dicho Valle de Calchaquí. Si se puebla". ${ }^{14}$ Esta última precisión es muy elocuente: la dejación no era un acto meramente altruista, contemplaba un objetivo concreto: el de poder por fin gozar de la fuerza de trabajo de los indios que formalmente estaban bajo su autoridad. Entre estos tributarios virtuales estaban precisamente los de Animaná. Si el citado título no estipulaba en detalle todos los pueblos de esa encomienda, los conocemos sin embargo gracias a un documento posterior que, por cierto, es particularmente ilustrativo del modo de transmisión hereditario de las encomiendas en el Tucumán y en las demás tierras de frontera. Se trata de la confirmación, el 20 de enero de 1635, de esa vieja encomienda al hijo de Pedro de Abreu y Figueroa, llamado Juan de Figueroa como su abuelo. ${ }^{15}$ A la muerte de su padre, éste heredó por dos vidas la encomienda familiar. Entre los pueblos supuestamente pacificados durante las campañas militares de los años 1630 aparecen los de Animaná, Bombolan y Famaillú, que se habían mantenido fuera del sistema colonial hasta entonces y habían tenido una participación activa en la puesta en jaque del nuevo intento de asentamiento. ${ }^{16}$

Ahora bien, crear nuevas encomiendas implicaba para las instancias coloniales crear nuevos cargos internos para su buena administración. En este caso, más que la identificación de una autoridad indígena, lo que nos proporciona el documento es, por lo tanto, la marca de un nombramiento funcional al sistema colonial. Retomemos el mismo caso de la confirmación de encomienda extendida a Juan de Abreu y Figueroa:

[...] Hago merced y encomiendo en el dicho Juan de Abreu y Figueroa por todos los días de su vida y la de su vida y la de su subcesor legítimo conforme a la ley de subcesión todos los pueblos y repartimientos que tubo por títulos de encomienda el dicho capitán don Juan de Abreu su abuelo en la dicha ciudad de Salta y su districto y jurisdicción y Valle de Calchaquí y Anguinahao y otras partes donde estubieren con lo anejo y perteneciente que señaladamente son los siguientes: el pueblo de palinda [?] y sus subjetos, el pueblo de Amimana con sus curacas, el pueblo de Bombolan con sus curacas el pueblo de Vilti [?] con don Pedro Vilti [?], el pueblo de Calian con sus curacas el pueblo de Famayux con sus curacas con mas todos los yndios que el dicho capitán don Juan de Abreu tubo por encomiendas de los governadores Juan Ramírez de Velasco don Pedro de Mercado y don Juan de Barrasa y en particular se entiende comprehenderse en el repartimiento y encomienda de los yndios que an estado y están rreduzidos visitados y empadronados en la dicha ciudad de Salta pertenecientes a los títulos de las dichas encomiendas y en las chacra y tierra del río segundo y en otras qualesquier partes con sus parcialidades tierras y aguadas y con el [...] y a los caciques y principales guardandoles las eçempciones de que deven goçar. ${ }^{17}$

A su vez, para matizar una afirmación que podría parecer un poco perentoria, tampoco puede excluirse sistemáticamente que dichos nombramientos se hayan amoldado jamás a la organización interna de los pueblos transformados 
en encomienda: nada indica que esos caciques/curacas registrados en esos documentos de encomienda no desempeñaban algún tipo de autoridad autónoma antes. Digamos por lo menos que, a falta de más datos, es imposible inferirlo mecánicamente de la función colonial que le otorga este tipo de documento.

El caso paradigmático de este tipo de impasse, para el Tucumán colonial, es el del cacique Calibay, quien supuestamente presentó motu propio un pedido de tierras ante las autoridades salteñas en 1586, pocos años después de la fundación de la ciudad en un periodo sumamente agitado y, caso muy singular, consiguió que el teniente de gobernador de turno accediese a su pedido. Calibay aparece presentado en este documento como "cacique principal del repartimiento de los Pulares" [y habla] en nombre de los demás caciques e yndios naturales de la comunidad de dichos los yndios pulares" ${ }^{18}$ Si hacemos una lectura literal del texto, no cabe duda de que "dimos con el jefe": ya tenemos a un cacique dotado con un cargo inmejorablemente representativo y que, por si fuera poco, entabla negociaciones exitosas con los representantes hispano-criollos de la incipientes ciudad de Salta. Sin embargo, un estudio interno y externo del famoso documento nos condujo -en otro trabajo- a poner en tela de juicio el carácter autónomo del poder del que aparecía revestido el cacique Calibay en el momento de la petición en cuestión (Giudicelli, 2013). Por lo menos dos elementos permiten poner en tela de juicio el margen de maniobra real de Calibay: a) el título de "cacique principal de repartimiento" es de por sí un cargo colonial; y b ) la negociación se da en un marco más que acotado y, sobre todo, signado por la heteronomía más completa: Bartolomé Valero, el teniente de gobernador de Salta quién otorgó la merced, era al mismo tiempo el encomendero de los mismos pulares del que Calibay era "cacique de repartimiento". Por tal motivo, tenía un interés directo en que "sus" indios ocupasen unas tierras, por otra parte estratégicas ya que controlaban el acceso a los Valles Calchaquíes desde el Valle de Lerma a través de la Quebrada de Escoipe.

Otros elementos de crítica interna confirman la sospecha de manipulación: no hay rastro de intérprete alguno, cosa totalmente inverosímil en una fecha tan temprana. Calibay hace alarde de un envidiable manejo del latín protocolar. ${ }^{19}$ Por fin, el examen del manuscrito muestra que el cacique dejó una firma abajo del documento con una soltura y elegancia incomparable con los dolidos garabatos del espadachín Bartolomé Valero, dato imposible de comprobar en las transcripciones publicadas. Lo que sí -y por eso hablábamos previamente de impasse- aunque haya en esta transacción un descarado conflicto de interés, abuso de poder y manipulación grosera, nada impide que el puesto colonial de "cacique de repartimiento" que ostentaba Calibay no haya replicado en el nuevo orden un cargo que él mismo ocupaba antes de la creación del repartimiento de los pulares. El problema es que es totalmente imposible de determinar, a falta de más elementos. Calibay aparece por primera y última vez en nuestras fuentes, no se le conoce sucesor alguno antes de varias décadas, lo que deja el campo abierto para todo tipo de especulaciones.

\section{Caciques de guerra}

La otra figura de jefe ineludible en el contexto particular de la cohabitación colonial es la del líder rebelde. La guerra es el otro contexto en el que les es fundamental a los autores de nuestras fuentes "dar con el jefe" -y proporcionar el nombre del jefe-, por razones que hacen obviamente al mantenimiento del
18. ABHS. Fondo de mercedes de tierras y solares, $\mathrm{n}^{\circ} 105$. Este documento fue publicado dos veces, Cornejo y Vergara (1938) y Bravo Herrera (2010), pero el documento original da cuenta más claramente de la naturaleza heterónoma de la transacción.

19. Evoca en particular una tierras que les pertecen de "ab initio". 
orden y a su estrategia personal de ascenso social. Para los caudillos, quienes redactaban esos informes y los dirigían a las autoridades administrativas españolas, era necesario demostrar que habían "pacificado" la tierra con el fin de conseguir una recompensa -dinero, un hábito militar, una encomienda, un puesto más importante en la administración, etc. Para nosotros es no menos esencial dar con esos jefes blandidos como trofeos -aunque en nuestro caso las perspectivas de ascenso sean francamente inferiores- porque la guerra es uno de los momentos privilegiados para observar la geopolítica indígena. Nos permite en particular analizar el desfase entre, por un lado, la situación movediza dada por la trama de alianzas indígenas y, por el otro, el encasillado colonial supuestamente fijo, hecho de encomiendas y pueblos registrados, que aparece totalmente desestabilizado (Giudicelli, 2007).

Lo que observamos con notable regularidad en esos momentos de crisis del orden colonial es que el juego de las alianzas entre grupos sublevados no corresponde en absoluto con las "naciones" y demás "parcialidades" delimitadas por las diferentes instancias del frente pionero colonial. Es por lo tanto un excelente observatorio, en la medida en que los numerosos documentos redactados al calor de la guerra -partes de campaña, correspondencia de todo tipo, autos de guerra, juicios expeditivos, informes de capellanes jesuitas, informaciones judiciales, etc.- entran muy seguido en contradicción frontal con el orden mudo que caracterizaba la situación anterior, la pax hispánica. Es asimismo uno de los escasos momentos en los que se puede observar en las fuentes la dinámica política indígena autónoma y, por tanto, determinar -si hay suerte- quiénes son los verdaderos instigadores de los sublevamientos, cómo se estructura el poder en esas sociedades indígenas y cómo se articulan las alianzas.

En esos documentos relativos a la pacificación se destacan, esquemáticamente, tres figuras sospechosas de jefes rebeldes. Estas tres figuras serían: el director de orquesta rojo, el bárbaro domado y el trofeo.

\section{El director de orquesta rojo}

El primero sería el cerebro de una conspiración de tal amplitud que ninguna autoridad colonial estaría en condiciones de preverla ni, mucho menos, de controlarla. El caso más conocido para los Valles Calchaquíes es el del cacique de Tolombón, Juan Calchaquí, a quién se le achacó la responsabilidad directa y personal en el sublevamiento general de 1562 que barrió la presencia española de toda la parte andina del Tucumán, causando la destrucción de todas las ciudades fundadas en los años anteriores -Cañete, Londres, Nieva y, sobre todo, la primitiva Córdoba, fundada en el corazón del valle del río Calchaquí, probablemente en las inmediaciones de la actual localidad salteña de San Carlos. Fue tal el impacto del sublevamiento de los diaguitas que se llegó a imputar a Juan Calchaquí la totalidad de los conflictos que convulsionaban el virreinato del Perú en ese entonces. La Audiencia de Charcas lo acusó no sólo de llevar la batuta en los ataques que sufrían los colonos en Tarija y Santa Cruz, a manos de los chiriguanos, en la quebrada de Humahuaca y las inmediaciones de Potosí sino también de estar confabulado con los incas rebeldes de Vilcabamba: “[...] a esta sazón se sonó que el Ynga estava confederado con calchaquí y con los chiriguanaes y que andaban persuadiendo a los caciques de todo el rreino para que se alçasen $[\ldots]^{\prime 20}$ 
El pavor suscitado por la ofensiva impuso entre los hispano-criollos la denominación de Valle de Calchaquí y de indios calchaquíes para calificar a los hasta entonces llamados "diaguitas de guerra", que supuestamente respondían a Juan Calchaquí. De lo poco que sabemos -no mucho en realidad- Juan Calchaquí parece haber tenido cierta influencia, un dato corroborado por lo que se verificó después en múltiples ocasiones de la capacidad de convocatoria del grupo tolombón-pacioca-colalao. ${ }^{21}$ Ahora, de allí a prestarle el poder ominoso que le atribuyeron los colonos del Tucumán y los oidores de la Audiencia de Charcas -por motivos que hacían a su propia agenda- ${ }^{22}$ hay un paso que la frecuentación de las fuentes inmediatamente posteriores impide dar. Las cosas parecen haber sido mucho más equilibradas y es muy poco probable que Juan Calchaquí, entronizado líder de dimensión continental, haya tenido un papel tan eminente de "mayor tirano que ha habido en estos reynos". ${ }^{23}$ Fue sin embargo esta perspectiva, que magnificaba el poder supuesto del cacique de Tolombón, la que prevaleció en el sentido común historiográfico y es la que todavía funda la imagen retrospectiva de Juan Calchaquí.

Si parece comprobado que la confederación de 1562 logró arrastrar a ciertos grupos de la Quebrada de Humahuaca, de los charcas y de los chichas (Palomeque, 2006), la conexión con los chiriguanos y con Vilcabamba es altamente improbable, por no decir que es un delirio originado tanto por el temor de los colonos del Tucumán como por el interés político de los oidores de Charcas.

Por otra parte, las disensiones internas al entramado geopolítico indígena de las que tenemos constancia en el Valle de Calchaquí en los años posteriores parecen apuntar a una estructura de poder mucho menos verticalista de lo que dejaría suponer esta perspectiva caudillófila. Sabemos, por ejemplo, que durante la campaña del gobernador Ramírez de Velasco de 1588 este grupo, cuyo poder tan sólo unos veinte años antes se proyectaba a la casi totalidad del virreinato del Perú, se encontró reducido a solicitar la alianza de los hispanocriollos contra sus vecinos del sur del mismo valle interandino. Es lo que se transparenta claramente en el informe del mismo Gobernador:

[...] di en una ranchería de hasta quatrocientos indios benediços de Londres los quales estavan fortificados por la guerra que traen en Calchaqui y entendida mi benida se subieron a la sierra [...] y este propio dia antes de levar el campo llegó a él Calchaquí con hasta ochenta indios y con otro presente y a ofrescer la paz y a pedir socorro contra los dichos quatrocientos indios de otros tanto questan en este asiento de Quiri quiri asimismo de los venedizos de Londres [... ${ }^{24}$

\section{El bárbaro domado}

La segunda figura de jefe rebelde es el anverso de la anterior: es el ex-rebelde transformado en aliado, al que se pasea de ciudad en ciudad, según el modelo de los triunfos romanos, y al que nunca se deja de mencionar en una relación de méritos y servicios. Se trata también de un caso muy común en la literatura colonial. Sin ir más lejos, entraría en esta categoría el mismísimo hijo de Juan Calchaquí, Siltipocle, quien fue exfiltrado del Valle de Calchaquí en 1588 por el gobernador Ramírez de Velasco después la ya mencionada "entrada" durante la que, como lo vimos, había solicitado el apoyo de las huestes coloniales.

Como era de esperar, este informe de campaña aparece con todo lujo de detalle en la relación de méritos y servicios del gobernador. Lógicamente, Siltipocle
21. Una capacidad que no se trata aquí de minorar, ni mucho menos; como sabemos, este grupo mantuvo una cohesión muy fuerte hasta el final de las guerras calchaquíes e incluso después de las campañas de desnaturalización de los años 16591665. Es más, fue el único capaz entonces de negociar en posición de fuerza con los hispano-criollos; una rendición a cambio del mantenimiento de una relativa autonomía y de la obtención de tierras en el Valle de Choromoros. Cruz (1997); Cruz (Ms.); López de Albornoz y Bascary (1996); al respecto es interesante el análisis de Rodríguez (en prensa, 2017) sobre la práctica de "doble asentamiento" que desarrollaron como estrategia de resistencia.

22. Estaban reivindicando una extensión de sus prerrogativas jurisdiccionales a expensas de la Audiencia de Lima.

23. Traslado de la Carta que la Audiencia de Charcas...10-06-1566, en Levillier (1918-1922: 443).

24. Carta del gobernador del Tucumán J. Ramírez de Velazco participando el resultado que hasta entonces tenía su expedición a las rancherías de Calchaqui, en Levillier (1920: 242). 
25. Información de servicios de Juan Ramírez de Velasco, 29-02-1589, en Levillier (1919-1920 (II): 438),

26. Relación de las paces que ante su señoría han hecho los naturales de esta gobernación, 18-04-1621, en Hackett (1923 (II): 122).

\begin{abstract}
27. Se trata de la ranchería de Cacalotichán, en el Valle de San Pablo. Véase el manuscrito de la Relación delo sucedido en la jornada que don Gaspar de Alvear y Salazar, cavallero del horden de Santiago hizo a los tarahumares desde los 26 de febrero deste año de 1619 hasta los 20 de abril del dicho año por el padre Alonso de Valencia, de la Compañía de Jesús, que acompañó el dicho campo, f. 2 v. (Benson Library, University of Texas, Latin American Collection, Varias relaciones, vol. 1). Para un análisis parcial de este texto, Giudicelli (2017).
\end{abstract}

28. En aquel entonces la figura magnificada había sido la de Tucumudagui, líder incontestable cuyas condiciones los hispanocriollos habían tenido que aceptar a falta de poder imponer una solución militar (Giudicelli, 2006). luce en ella como el cacique por antonomasia, el más importante, el más influyente, etc. En contradicción con lo que él mismo Ramírez de Velasco había expuesto en su propio informe de campaña, un documento que obedecía a otra lógica y donde recalcaba por el contrario la situación delicada en la que se encontraba el heredero en apuros del legendario Juan Calchaquí, al que califica ahora de "cacique principal del dicho Valle". ${ }^{25}$

La historia de las guerras de frontera -o mejor dicho este tipo particular de documentos que son los informes de guerra y las relaciones de méritos y servicios- presentan un sinfín de casos similares. Observemos, para los mismos años, otro escenario bélico en el otro extremo de la América española. En enero de 1621 otro caudillo español, Francisco Montaño de la Cueva veterano y mandamás de la provincia de la Nueva Vizcaya, relata el sofocamiento de un nuevo conato de rebelión nacido en la estela de la guerra de los tepehuanes. Presenta en su informe como nuevo aliado a un tal Juan Cocle al que no duda en entronizar "rey de toda la nación taraumar en cantidad de quatro mil Yndios". ${ }^{26}$ Un hallazgo apreciable en una perspectiva de pacificación y una situación soñada para quien busque con ansia identificar en el siglo XXI, con cierto modelo de antropología política en mente, la cabeza de alguna jefatura, por ejemplo.

Lamentablemente, basta con diversificar un poco el tipo de documentos de archivos para darse cuenta de que esta perspectiva no se sustenta en nada. Para la fecha en la que escribía el caudillo Montaño de la Cueva, Juan Cocle era todo menos un desconocido: dos años antes, en la última gran campaña contra los tepehuanes y tarahumaras del Valle de San Pablo, los partes del mismo Montaño de la Cueva mencionaban a este individuo como uno de los dos caciques de una ranchería muy reducida. ${ }^{27}$ Con el cambio de las circunstancias coloniales, ya aparece como rey de una nación tarahumara. Dos conceptos que nada tienen que ver con la organización política de las sociedades rarámuri pero que expresan muy bien la preocupación de las autoridades hispanocriollas por nombrar responsables afines. Juan Cocle no representaba nada: si se lo entronizó es porque en aquella ocasión había hecho de intermediario para que los verdaderos líderes de la rebelión condescendieran en negociar con los hispano-criollos las condiciones de la paz, desde una posición muy favorable por cierto ${ }^{28}$ Huelga decir que no se volvería a mencionar después a ese Juan Cocle, ni tampoco se hablaría de ningún "rey tarahumara".

\section{El trofeo}

Última figura sospechosa de jefe rebelde: el cacique-trofeo. En este rubro también abundan los ejemplos. Esos trofeos aparecían por lo general en varias partes, las más veces bajo la forma de una cabeza plantada en una pica o atada a la silla de algún caballo antes de ser colocada en una picota o en alguna plaza pública para "escarmiento" de todos. En los casos más graves, eran directamente descuartizados y los trozos de su cuerpo expuestos en el lugar de sus delitos. El "gran alzamiento" que sacudió a toda la región interandina en los años 1630 empezó por cierto con una serie de suplicios públicos contra los responsables del ataque sangriento contra un encomendero de Salta, un tal Juan Ortiz de Urbina en Accibí, cerca de la actual Seclantás. En esta ocasión, el gobernador Felipe de Albornoz no dejó de trasmitir al rey la macabra cuenta de dicha operación pedagógica: 
Prendí luego los más principales delincuentes de todos y, hecha la averiguación de sus culpas conforme a derecho, [...] hice justicia de diecisiete dellos en el mismo lugar, día y hora donde ellos mismos mataron al dicho Juan Ortiz de Urbina y más españoles. [...] después de ahorcados fueron flechados y quemados sus cuerpos y las cabezas puestas en palos para escarmiento de los demás [...] Los [indios] que se hallaron menos culpados unos fueron desgarronados, a otros se les cortó por la primer coyuntura el dedo pulgar de la mano derecha, a otros los picos de las narices y a otros se tresquilaron, azotaron y clavaron la mano. ${ }^{29}$

Los caciques-trofeos constituyen, por supuesto, un boccato di cardinale para los agentes de la pacificación que pueden atribuirse su reducción. También podríamos multiplicar los ejemplos en todos los escenarios de frontera. Nos limitaremos a dos casos, por el peso que tuvieron en la narrativa de la pacificación respectivamente en la guerra de los tepehuanes en la Nueva Vizcaya y en el Gran Alzamiento diaguita en el Tucumán.

En 1618, una columna mandada desde Durango, capital de la Nueva Vizcaya, dio por casualidad en una quebrada de la Sierra Madre Occidental con una partida reducida de indios liderados, al parecer, por un tal Francisco Gogojito. En cuestión de minutos éste fue rápidamente acribillado a flechazos por los indios amigos y decapitado ante el regocijo general, en particular del capellán jesuita Alonso de Valencia quien dejó una descripción muy gráfica de la atmósfera de alegría que siguió este expeditivo ajusticiamiento: “[...] yo tomé [la cabeza] de Gogojito, que aun estaba caliente y de rodillas, acompañándome en la propia actitud todo el campo, dije el te deum laudamus". ${ }^{30}$

Unos veinte años después, en lo que sería hoy el oeste catamarqueño, el maese de campo Pedro Ramírez de Contreras se ufana de una acción similar con la captura y ejecución de Juan Chalimín, cacique de los malfines que había causado muchos problemas a las tropas hispano-criollas.

[...] el dicho maese de campo le condenó a muerte e hizo cuartos en su propio pueblo y horca y clavó su cabeza en el rollo de la ciudad de La Rioxa donde oi está, y en el de ésta [Poman] asimesmo mandó clavar su brazo derecho para escarmiento y ejemplo de otros $[\ldots]^{31}$

En ambos casos el suplicio ejemplar venía justificado por el abultado prontuario del muerto, que sus vencedores se apresuraban en detallar. El caso de Chalimín era particularmente grave -y por lo tanto redituable para su vencedor- ya que acumulaba todos los delitos de lesa majestad, habidos y por haber:

\footnotetext{
[...] Chalemín, cabeza y caudillo de los rebeldes [...] quien a sustentado la guerra mas tiempo de seis años, siendo causador y movedor del primer alzamiento desta provincia y el que despobló la dicha ciudad de San Juan a cavo de veinte y quatro años que se havia conservado, teniendo en su pueblo horca y arbol de justicia levantado en que ahorcava los indios gente que le parecía eran afectas a los españoles y hecho otros atrozísimos delitos [...].32
}

El problema es que la omnipotencia póstuma de esos jefes-trofeos aparece amplificada por su contexto de aparición. Las más veces esos despojos gloriosos son un ornamento obligado en partes de pacificación y relaciones de méritos y servicios -documentos cuya finalidad implica necesariamente una maximización de la peligrosidad y, por tanto, del valor agregado de esas víctimas-trofeos. La cabeza de Chalimín, por ejemplo, apenas sobresale entre los
29. Carta del gobernador de Tucumán Felipe de Albornoz 29-04-1631, en Rodríguez Molas (1985: 148). Prueba de que esta pedagogía del terror no siempre surtía el efecto deseado, esta represión desencadenó la guerra más dura y cruenta en la región desde 1562 .

30. Carta de Alonso de Valencia, en Naylor y Polzer (1986 (I): 274).

31. AHPC. Esc. 2, Leg. 6, T. I, Exp. 2, Servicios del maese de campo Ramírez de Contreras. Transcripta en parte en Montes (1961: 140-142).

32. AHPC. Esc. 2, Leg. 6, T. I, Exp. 2, Servicios del maese de campo Ramírez de Contreras. Transcripta en parte en Montes (1961: 140-142). 
33. AHPC. Esc. 2, Leg. 6, T. I, Exp. 2, Servicios del maese de campo Ramírez de Contreras. Transcripta en parte en Montes (1961: 140-142).

34. El gobernador de la Nueva Vizcaya, Alonso de Alvear y Salazar, se vanagloria de que sus capitanes hayan eliminado a "[...] uno de los más belicosos capitanes de los Tepehuanes Ilamado Gogojito". Relación breve y succinta de los sucesos que ha tenido la guerra de los Tepehuanes de la governación de la Nueva Vizcaya desde 15 de noviembre de 1616 hasta 16 de mayo de 1618, en Hackett (1923 (II): 110).

35. Roxana Boixadós (2011) analiza una junta de guerra que reúne a varios caciques que abarcan desde los grupos más meridionales del Valle de Calchaquí hasta algunos pulares, evidenciando así la fluida diplomacia de guerra que fundaba la geopolítica indígena, desde el Valle de Anguinahao hasta el extremo norte de los valles interandinos del Tucumán. Sobre los malfines desnaturalizados, González Navarro (2015); Lorandi y Sosa Miatello (1991) y Quiroga (2010).

36. AHPC. Esc. 1, Leg. 79, Exp. 1 y AHPC. Esc.. 1, Leg. 94, Exp. 7. (Véase nota 8). condenados de Pedro Ramírez de Contreras quien, según sus propias palabras, "[dejó] indios ahorcados por todos lados", ${ }^{33}$ una acción de represalias rigurosamente igual en el caso neovizcaíno citado anteriormente. En otras palabras, su aparición en este tipo de texto no es un indicador fidedigno de la autoridad que ejercía o dejaba de ejercer realmente antes de su ejecución. Por su parte, el que se hayan multiplicado las acusaciones en su contra tampoco alcanza, como tampoco es suficiente la conservación de su figura en la narrativa histórica sobre el evento. Se pudo demostrar, por ejemplo, que la rabia contra Gogojito que reboza de las palabras del jesuita que describió su ajusticiamiento no se debía tanto a su estatus en la sociedad tepehuana como al hecho de que era un indio ladino del pueblo misional de Santiago Papasquiaro, quien había tenido un papel destacado en su destrucción. ${ }^{34}$

El problema sigue entero: ¿cómo "dar con el jefe" si los que aparecen en nuestras fuentes sirven ante todo para enriquecer las fojas de servicios de espadachines y caudillos, adornar las páginas ejemplares de los misioneros soldados o decorar las plazas públicas de las ciudades locales con sus despojos mortales? Es difícil pero no imposible. Si retomamos el caso de Juan Chalimín, y si nos atenemos a nuestra duda metodológica, no nos queda otra solución que buscar en otro tipo de materiales la confirmación de la estatura que les prestan los responsables de la pacificación. Sin embargo, en este caso preciso contamos con dos elementos que parecen confirmar la hipótesis del papel político destacado de Chalimín:

1) Un argumento etnohistórico comprobado desde hace ya cierto tiempo en la historiografía: la reconstrucción de las alianzas evidencia la posición pivote de su grupo -los malfines- en la trama que ponía en continuidad desde mucho antes del Gran Alzamiento a los del sur del Valle Calchaquí -ingamanas, tucumangastas y yocaviles, en particular- con los de la provincia en principio sometida de los diaguitas -andalgaláes, abaucanes etc.- (Schaposchnik, 1997; Boixadós, 2011)..$^{35}$

2) La existencia de un documento muy posterior conservado en el archivo de Córdoba, la demanda de don Ramiro, hijo de Chalimín, contra un primo de su padre, un tal Sebastián Utisa Mayo, a quien acusa de usurpar el cargo de cacique que le toca por vía hereditaria, lo cual despeja gran parte de las dudas que se podía tener acerca de la realidad del poder de Chalimín, más allá de las fanfarronadas de su vencedor. ${ }^{36}$

\section{Conclusiones}

Reconstituir la trama política del grupo considerado -que debería ser el objetivo de una perspectiva etnohistórica- supone, ante todo, un doble trabajo crítico sobre las mismas fuentes y sobre la manera de encararlas, incluso antes de privilegiar uno u otro marco teórico-metodológico.

Supone primero una identificación del contexto de producción de los documentos, a fin de desentrañar si se trata de una identificación de alguna autoridad interna a la sociedad indígena o de un nombramiento funcional a la administración y el control del frente colonizador. Implica un estudio pormenorizado del fondo documental en el cual apareció la figura de ese "cacique", "reyezuelo" o "principal", para tratar de ver qué papel desempeña dicha figura en la economía de ese conjunto documental: no es lo mismo un legajo que compila mercedes de tierras y títulos de encomienda que un expediente 
judicial relativo a la separación de alguna encomienda; es profundamente distinto el parte de guerra de tal jesuita que oficia de capellán en una columna de "pacificación" que su inclusión corregida en la Carta Anua, prolijamente expurgada y editada por la Compañía de Jesús.

El segundo trabajo, no menos importante, es de índole reflexiva. Apunta a desconfiar de marcos teóricos y rejas de lecturas tipológicas que nos incitan a escudriñar en los archivos elementos para confirmar lo que estamos buscando de antemano. Para el caso que nos ocupa, el peligro sería el de proyectar demasiado nuestras esperanzas de encontrar respuestas para expectativas sobre, por ejemplo, la estructura sociopolítica de los grupos indígenas - ¿jefatura, grupo étnico, sociedad segmentaria?- o sobre la capacidad de esos mismos grupos de llevar una palabra autónoma en un contexto de coerción, apelando a conceptos que si bien no carecen de cierto valor heurístico a veces casi anteponen la respuesta a la pregunta, pues proporcionan unas situaciones predefinidas o definidas para contextos muy diferentes del que uno estudia. Así la sana voluntad de rescatar la "agencia" de unos y otros y el encomiable deseo de restaurar en las fuentes unas "interpelaciones mutuas" entre grupos indígenas e instancias coloniales puede terminar opacando la realidad de las relaciones de fuerza que imperaban en el momento estudiado $y$, sencillamente, impedir la percepción de una distribución del poder que no necesariamente se encarnaba exclusivamente en la persona de un jefe. Del mismo modo, para tomar otro ejemplo, si bien el middle ground acuñado por Richard White (White 1991) para la región de los Grandes Lagos en los siglos XVII y XVIII y las interacciones entres franceses y grupos indígenas es un concepto tentador y muy interesante, no puede tener vigencia para confines como el Tucumán y la Nueva Vizcaya en los siglos XVI y XVII. ${ }^{37}$ Ahí donde los franceses buscaban alianzas -si bien asimétricas- e interlocutores para garantizar sus relaciones comerciales en la tierra adentro, la dinámica de conquista y colonización hispano-criolla implicaba un grado de confrontación mucho más importante. Estas dos dinámicas arrojan resultados muy distintos en la aparición de las autoridades indígenas en los registros coloniales: los agentes coloniales de la Nueva Francia tenían un interés directo en identificar a los que tuvieran una influencia real en una tierra que ellos no controlaban, mientras la política de ocupación territorial y de sujeción propugnada por los hispano-criollos implicaba una intervención infinitamente superior en la segmentación heterónoma de las sociedades indígenas, recortando grupos y nombrando caciques.
37. Para una reseña crítica del concepto ver Havard Gilles (2010). 


\section{Notas}

3. El AGI es asimismo un repositorio esencial para la misma problemática en la Nueva Vizcaya -ramos Guadalajara, México, Indiferente General, Escribanía de Cámara-; además existen numerosísimos legajos en la Galería 4 del Archivo General de la Nación en México (AGN, México) -Historia, Jesuitas, Inquisición, Indios...-, en la Biblioteca Nacional de México (BNM) -Fondo Franciscano- así como en varios archivos provinciales: el Archivo Histórico de Durango, en Durango (AHD), el Archivo Histórico del Municipio de Parral, en Chihuahua (AHP) y, en menor medida, en el Archivo Histórico de Zacatecas (AHZ) y el Archivo Histórico de la Provincia de Jalisco (AHJ). También, la Benson Library de la Universidad de Texas, en Austin Estados Unidos, posee varios manuscritos de importancia para la historia colonial del norte de México, en general, y para la cuestión que nos ocupa, en particular. Por último, al ser los jesuitas los principales agentes misioneros en ambas regiones, es fundamental conocer sus escritos. Muchas crónicas y Cartas Anuas fueron publicadas, pero el Achivum Romanum Societatis lesu (ARSI) de Roma presenta al investigador un sinfín de documentos más técnicos y confidenciales que permiten una mirada más fina del trabajo de reducción y de transformación social llevado a cabo por la Compañía. El fondo Jesuitas del AGN de México ofrece también documentación de fundamental importancia -los "puntos de Anuas" centralizados por los provinciales antes de la redacción de las Cartas Anuas propiamente dichas. En el presente trabajo, si bien remitiremos con frecuencia a esos fondos de archivo, no podremos, por razones obvias de espacio y por el carácter sintético del mismo, ofrecer una presentación exhaustiva de todas y cada una de las fuentes. Por otra parte, para facilitar el acceso a las mismas hemos optado por dar, cada vez que fuera posible, la referencia a una versión publicada: no se trata en absoluto de fuentes secundarias sino de versiones paleografiadas durante misiones oficiales financiadas en las primeras décadas del siglo XX. Para el Tucumán, Roberto Levillier publicó numerosísimos volúmenes en la década de 1920, pero muchos documentos sin publicar se encuentran en el Fondo García Viñas de la Biblioteca Nacional de Buenos Aires (BNBA), en la biblioteca del Museo Etnográfico de la Universidad de Buenos Aires (UBA) y en la Biblioteca del Instituto Ravignani de la Facultad de Filosofía y Letras (FFyL) de la UBA. Sobre el papel de Gaspar García Viñas en este ingente trabajo de compilación de documentos del AGI Buenos Aires, véase Rey (2014). Para la Nueva Vizcaya, los volúmenes de fuentes publicados por Charles W. Hackett (1923) y Naylor y Polzer (1986) son asimismo valiosos compilados de textos de difícil acceso. Ahora bien, como las versiones paleografiadas no siempre están exentas de errores señalaremos cuando nos parece que la versión publicada es bien incompleta y ambigua y remitiremos al original. (En página 19). 


\section{Dondos de archivos citados consultados}

»ABNB: Archivo y Bibliotecas Nacionales de Bolivia (Sucre, Bolivia)

» ABHS: Archivo y Biblioteca Históricos de Salta (Salta, Argentina)

» Benson Library, University of Texas (Austin- Texas, Estados Unidos)

» BNBA-García Viñas: Fondo García Viñas de la Biblioteca Nacional (Buenos Aires, Argentina)

»AGI: Archivo General de Indias (Sevilla, España)

» AGN: Archivo General de la Nación (Buenos Aires, Argentina)

»AHPC: Archivo Histórico de la Provincia de Córdoba (Córdoba, Argentina)

»AHT: Archivo Histórico de Tucumán (San Miguel de Tucumán, Argentina)

»ARSI: Archivum Romanum Societatis lesu (Roma, Italia) 


\section{Q Bibliografía}

" Boixadós, R. (2011). "Rebeldes, soldados y cautivos. Etnografía de un episodio en la frontera de guerra del Valle Calchaquí (1634)" en Rodríguez, L. (comp.), Resistencias, conflictos y negociaciones 93-121. Rosario, Prohistoria.

"Bravo Herrera, F. E. (2010). El Fondo de mercedes y solares del Archivo y Biblioteca Históricos de Salta. Salta, Fondo CAPACIT-AR del NOA.

»Cornejo, A. y M. A Vergara (1938). Mercedes de tierras y solares (1583-1589). Salta, Imp. San Martín.

"Cruz, R. (1997). "El fin de la 'ociosa libertad'. Calchaquíes desnaturalizados a la jurisdicción de San Miguel de Tucumán en la segunda mitad del siglo XVII" en Lorandi, A. M. (comp.), El Tucumán y Charcas (II): 215-264. Buenos Aires, Facultad de Filosofía y Letras (FFyL), Universidad de Buenos Aires (UBA).

"Cruz, R(s/f). "La evolución de la propiedad comunal de los calchaquíes desnaturalizados a la jurisdicción de San Felipe de Salta y San Miguel de Tucumán (1660-180o)". Ms.

"Cunill, C. (2015). Philip II and Indigenous Access to Royal Justice: Considering the Process of Decision-Making in the Spanish Empire. Colonial Latin American Review 24 (4): 505-524.

»Documentos para la Historia de Argentina (1927-1929). Buenos Aires, Instituto de Investigaciones Históricas Dr. Emilio Ravignani, FFyL, UBA.

»Foucault, M. (2002 [1976]). Vigilar y castigar. Buenos Aires, Siglo XXI.

»Giudicelli, C. (2006). Un cierre de frontera...taxonómico. Tepehuanes y tarahumara después de la guerra de los tepehuanes (1616-1631). Anuario del IEHS 21: 59-78.

»Giudicelli, C. (2007). Encasillar la frontera. Clasificaciones coloniales y disciplinamiento del espacio en el área diaguito-calchaquí (Siglos XVI-XVII). Anuario del IEHS 22: 161-212.

» Giudicelli, C. (2013). Calibay o la tempestad. Debate en torno a un documento 'indígena' de la Salta primitiva. Corpus 3 (1): Disponible en Internet: http://journals.openedition. org/corpusarchivos/336; DOI: 10.400o/corpusarchivos.336. Consultado el 26 de mayo de 2014 .

" Giudicelli, C. (2017). Le cabinet en campagne, chroniques jésuites de 'pacification', Tucumán et Nouvelle Biscaye XVIle siècle”. e-Spania. Disponible en Internet: http://espania.revues.org/26320; DOI: 10.4000/e-spania.26320. Consultado el 19 de julio de 2017.

"González Navarro, C. (2015). “Los indios desnaturalizados del Valle de Calchaquí en Córdoba de rebeldes a fieles soldados del pueblo de San Joseph de los Ranchos (siglos XVII-XVIII)" en Salazar, J. (ed), Condiciones de posibilidad de la reproducción social en sociedades prehispánicas y coloniales tempranas en las Sierras Pampeanas (República Argentina): 151-176. Córdoba, CESH - Prof. S. A. Segreti.

" Hackett, C. W. (ed.) (1923). Historical documents relating to New Mexico, Nueva Vizcaya and approaches thereto, to 1773 . Washington, D.C., The Carnegie Institution of Washington.

" Havard G. (2010). [Reseña de] Richard White, Le Middle Ground. Indiens, Empires et Républiques dans la région des Grands Lacs, 1650-1815. Toulouse-Anacharsis, 2009. Revue d'histoire moderne et contemporaine 57 (1): 204-206.

"Lamana, G. (2008). Domination without Dominance. Inca-Spanish En- counter in Early Colonial Peru. Durham and London, Duke University Press. 
"Levillier, R. (ed.) (1918-1922). Audiencia de Charcas, Correspondencia de presidentes y oidores. Madrid, Impr. de Juan Pueyo. (3 vols.).

»Levillier, R. (ed.) (1919-1920). Probanzas de méritos y servicios de los conquistadores. Madrid, Sucesores de Rivadeneyra. (2 vols.).

» Levillier, R. (ed.) (1920). Gobernación del Tucumán, Papeles de gobernadores en el siglo XVI. Madrid, Impr. de Juan Pueyo. (2 vols.).

» López de Albornoz, C. y A. Bascary (1996). Pueblos indios de Colalao y Tolombón: Identidad colectiva y articulación étnica y social (siglos XVII-XIX). Humanitas 27: 71-112.

»Lorandi, A. M. y R. Boixadós (1987-1988). Etnohistoria de los Valles Calchaquíes. Runa XVII-XVIII: 263-420.

»Lorandi, A. M. y S. Sosa Miatello (1991). El precio de la libertad. Desnaturalización y traslados de indios rebeldes en el siglo XVII. Memoria Americana. Cuadernos de Etnohistoria 1: 7-28.

» Maldavsky, A. (2012). Vocaciones inciertas. Misión y misioneros en la provincia jesuita del Perú en los siglos XVI y XVII. Madrid, CSIC-IFEA.

" Montes, A. (1961). "El gran alzamiento diaguita", Revista del Instituto de Antropología 1: 81-159. Rosario, Universidad del Litoral.

"Naylor, T. H. y C. W. Polzer (eds.) (1986). The Presidio and Militia on the Northern Frontier of New Spain. A Documentary History (I): 1570-1700. Tucson, The University of Arizona Press.

» Palomeque, S. (2006). La 'historia' de los señores étnicos de Cochinoca y Casavindo. Andes 17: 139-194.

» Quiroga, L. (2010). En sus huaycos y quebradas: formas materiales de la resistencia en las tierras de Malfín. Memoria Americana. Cuadernos de Etnohistoria 18: 185-209.

» Rey, M. (2014). El copista: Gaspar García Viñas entre la Biblioteca Nacional y la Facultad de Filosofía y Letras. Buenos Aires, Teseo-Biblioteca Nacional.

》 Rodríguez, L. (2017). Efectos imprevistos de las desnaturalizaciones del Valle Calchaquí. El 'doble asentamiento' como estrategia de resistencia. Chungara 49: 1: o0-oo.

"Rodríguez, L. (ed.) (2011). Resistencias, conflictos y negociaciones. El Valle Calchaquí desde el periodo prehispánico hasta la actualidad. Rosario, Prohistoria.

» Rodríguez Molas, R. (ed.) (1985). Los sometidos de la conquista. Buenos Aires, Centro Editor de América Latina.

"Schaposchnik, A. E. (1997). "Aliados y parientes. Los diaguitas rebeldes de Catamarca durante el gran alzamiento" en Lorandi, A. M. (comp.), El Tucumán y Charcas (I): 309-340. Buenos Aires, FFy L, UBA.

"White, R. (1991). The Middle Ground. Indians, Empires and Republics in the Grat Lakes Regions. 1650-1815. New York, Cambridge University Press.

"Wilde, G. (2013). Introducción. Corpus 3 (1): Disponible en Internet: http://journals. openedition.org/corpusarchivos/336; DOI: 10.4000/corpusarchivos.336. Consultado el 4 de abril de 2014. 